\title{
Programa de Gestão do Patrimônio Arqueológico do município de São Sebastião
}

Clayton Galdino*

\begin{abstract}
GALDINO, C. Programa de Gestão do Patrimônio Arqueológico do município de São
Sebastiāo. Revista do Museu de Arqueologia e Etnologia, São Paulo, Suplemento 11: 183-188, 2011.
\end{abstract}

Resumo: Sob orientação da professora Maria Cristina M. Scatamacchia, o presente trabalho tem como objetivo oferecer bases para a consolidação de políticas públicas para o patrimônio arqueológico no município de São Sebastião, SP. Para tal, preconiza as ações de reconhecimento e gestão da arqueoinformação, a aplicação e proposição de diplomas legais, a curadoria do acervo e a co-gestão do patrimônio arqueológico pela comunidade. Tal iniciativa já obteve resultados parciais que delineiam seus objetivos finais.

Palavras-chave: Gestão do patrimônio arqueológico - Arqueologia pública - Sistemas de informação.

$\mathrm{O}_{\mathrm{d}, \mathrm{sen}}^{\mathrm{s}}$ bservamos, atualmente, manifestações de preocupação frente a impactos que novos fatores causam no nosso ambiente. No caso do urbanismo, algumas regiōes apresentam crescimento e transformação com velocidade acima da capacidade de acomodação ou adaptação por parte da sociedade e de seus recursos.

Temos em São Sebastião - cidade do litoral norte do estado de São Paulo, com cem quilômetros de costa, estreita faixa de terra cerceada por mar e montanhas, com inúmeros locais de grande beleza natural - um exemplo desse processo. Diante desses novos agentes, a região assiste à rápida transformação urbana e social, fatores que demandam açōes e estudos para que se garantam a preservação, compreensão e fruição das manifestações culturais presentes e das ocupaçōes de outrora.

(*) Museu de Arqueologia e Emologia da Universidade de São Paulo. Mestrando em Arqueologia. <galdinoarqueo@usp.br>
Diante desse cenário, apresentei ao Museu de Arqueologia e Etnologia da Universidade de São Paulo o Programa de Gestão do Patrimônio Arqueológico de São Sebastião, tema de projeto de mestrado, cujo objetivo principal é reconhecer o patrimônio arqueológico do município. Em aplicação desde o ano de 2008, tal iniciativa já obteve resultados parciais que delineiam seus objetivos finais.

Para a definição do escopo desse programa de gestão, utilizaremos como base as experiências implantadas pela Profa. Dra. Maria Cristina Mineiro Scatamacchia no Projeto Arqueológico do Baixo Vale do Ribeira, São Paulo (Scatamacchia 2008). A iniciativa contemplou, em sua idealização e execução, procedimentos como a identificação de panoramas regionais, gestão da informação e práticas de disponibilização do patrimônio arqueológico, entre as quais salientamos a utilização deste recurso como subsídios à atividade turística. 
O referido programa também tem como premissa estabelecer bases para a proteção integral do patrimônio arqueológico por meio de subsídios a todas as etapas da pesquisa, dentro do conceito definido pelo Prof. Dr. José Luiz de Morais como "Ciclo Completo de Curadoria" 1 que contempla não somente as etapas da pesquisa arqueológica, mas inclui a disponibilização à sociedade.

Assim, esse programa possui cinco bases: reconhecimento, gestão e disponibilização da arqueoinformação, proteção legal, curadoria e disponibilização do patrimônio arqueológico, conforme descritas.

Os trabalhos de reconhecimento do patrimônio arqueológico baseiam-se na etapa de campo, referente ao levantamento amostral do território sebastianense. Esta visão ampla possibilitará a compreensão aprofundada de cada sítio, em projetos específicos. O percorrimento geográfico proposto (sentido norte - sul) resultou na identificação de 25 sítios arqueológicos, na inserção de quatro sítios já cadastrados anteriormente nos sistemas de banco de dados e na descoberta de cinco áreas de ocorrência arqueológica, além de bens culturais integrados. Sem a pretensão inicial de oferecer estudos aprofundados sobre cada sítio, algumas lacunas sobre a ocupação do território sebastianense começaram a ser preenchidas, como a descoberta do sítio précolonial no núcleo urbano central (Sítio Cemitério Central - 01) e de ocupações coloniais possivelmente unifamiliares em cotas altimétricas elevadas e em terrenos distantes dos núcleos urbanos (sítios Boa Vista - 01 e Antão Soares - 01).

As ocorrências e sítios arqueológicos identificados alimentarão as ferramentas de gestão, bancos de dados em fase de testes e seu aprimoramento (SIG, SIGWeb e Inventário Digital do Patrimônio Cultural). Tais ferramentas são desenvolvidas em parceria com o setor de análise de sistemas da Fundação Cultural São Sebastião. Dado o caráter dinâmico da gestão da arqueoinformação, os SIGs devem ter como premissa básica a flexibilidade. Assim, devem a qualquer momento incorporar novos levantamentos cartográficos e novos documentos, característica

(1) Comunicação pessoal realizada em aula da Disciplina MAE-USP "Arqueologia da Paisagem", em 22 de agosto de 2006. necessária apontada por José Luiz de Morais (1992: 155). O professor também aponta que as chamadas geotecnologias, "permitem-nos a produção de alta qualidade com economia" (1999: 13).

Para a elaboração do banco de dados geográficos, utilizamos o gvSIG, software livre, desenvolvido pela Generalitat Valenciana da Espanha. Para sua utilização não é necessário registro nem há restrições quanto ao tempo de uso e distribuição. Interage com outros softwares, como o AutoCAD ${ }^{\circledR}, \operatorname{ArgGIS}^{\circledR}$, dentre outros, sem alterar seu formato, e fornece a possibilidade de adaptação de suas características segundo a demanda da organização que o utiliza.

Os dados coletados e sistematizados através de ferramenta SIG serão disponibilizados pelo produto denominado SIGWeb (Chagas 2010a), desenvolvido para ser operado via rede mundial de computadores (Fig. 1). O sistema prima pela interatividade e tem caráter intuitivo, oferecendo facilidade de navegação. Nesta plataforma, o usuário poderá posicionar territorialmente os bens culturais e cruzar informações (topografia, hidrografia, limites administrativos etc.) com diversas layers (camadas de informação).

Futuramente, implementaremos a filosofia de trabalho que parte da informação macro (localização do bem cultural) para as informações micro (ficha de inventário com os dados do patrimônio determinado). Esta etapa será possível com a integração do SIGWeb com o Programa de Inventário Digital do Patrimônio Cultural (Chagas 2010b). As fichas de inventário possuirão linguagem técnica acessível, pois foram concebidas com o objetivo de oferecer informação de forma clara e atraente. Fornecerá dados obrigatórios, tendo como base as fichas de registro do Cadastro Nacional de Sítios Arqueológicos CNSA, gerenciado pelo Iphan.

A última parte do documento será destinada à "construção de cenários". conforme vemos na obra do arqueólogo Paulo Eduardo Zanettini (2003). Nesse espaço permitiremos certa licença artística, como, por exemplo, a visualização de desenhos, vídeos, fotos e maquetes eletrônicas, quando disponíveis. Enfim, um viés pedagógico, que tem como objetivo maior aproximar os dados técnicos da compreensão, sobretudo visual, do usuário.

A catalogação de bens culturais mostrase como importante ferramenta de proteção, 


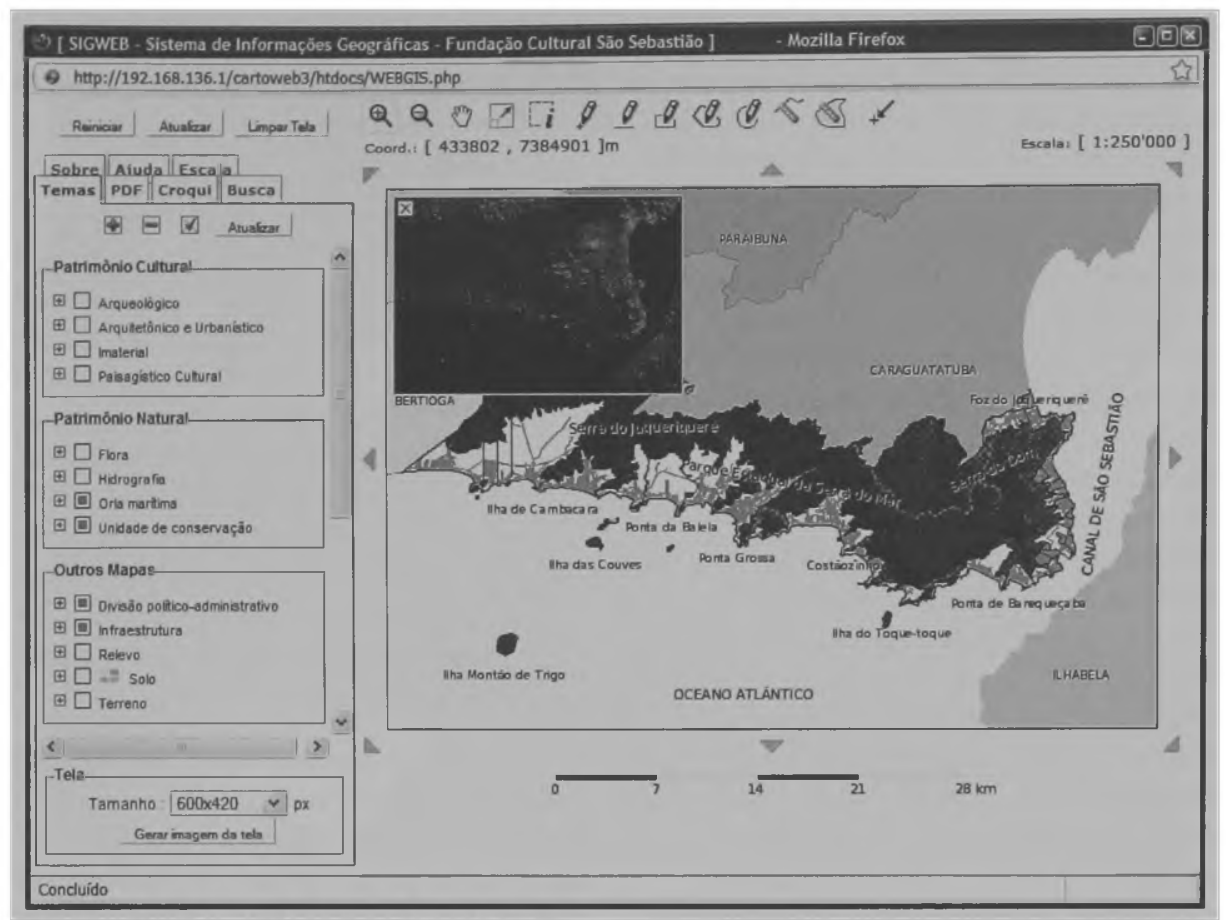

Fig. 1. Tela do SigWeb. Fonre: Jorge Luiz Chagas.

pesquisa e disponibilização uma vez que proporciona a organização dos dados e auxilia na produção de políticas públicas. Como proteção, entendemos que está presente na prevenção pelo conhecimento desses bens e no auxílio à participação popular, inclusive sob prerrogativa legal, pois "a visão constitucional valoriza a informação, já que, somente por meio desta, a participação da comunidade pode ser efetiva" (Soares 2007: 28). A autora ainda defende o caráter preventivo e sistematizador do inventário como instrumento de proteção ao afirmar que:

"Os inventários gerais de potencial arqueológico constituem instrumentos de trabalho essenciais para elaborar estratégias de proteçāo ao patrimônio arqueológico. Ao mesmo tempo, constituem fontes primárias de dados para pesquisa e estudos científicos" (2007: 29).

O conhecimento gerado demanda duas necessidades: a proteção e a disponibilização. Para promover a proteção do patrimônio arqueológico, pretendemos abordar, na segunda etapa, aspectos de ordenamento jurídico incidente. Esta ação demandará a análise da legislação atual e fornecerá subsídios para, se for o caso, propor diplomas complementares em âmbito municipal, seguindo os preceitos federativos cooperativos da União. Compõe ainda nosso objetivo instruir os órgãos fiscalizadores e os empreendedores sobre o ordenamento jurídico que deve ser aplicado em empreendimentos.

Concernente à curadoria do acervo arqueológico, entendemos que este é composto não somente dos vestígios exumados, mas também pela produção cultural incidente, pois, nas palavras de Rossano Lopes Bastos apud Soares (2007: 54), "o patrimônio arqueológico é assim integrado não só por bens materiais (artefatos de pedra, osso, cerâmica, restos de habitação, vestígios de sepultamentos funerários), mas também e principalmente pelas informações dele dedutíveis." Dessa forma, incluiremos no rol de bens a serem gerenciados produções artísticas (reinterpretaçōes, obras artesanais etc.) oriundas de projetos culturais que têm como tema o patrimônio arqueológico, o acervo documental e bibliográfico e, finalmente, o acervo didático, destinado à construção de dioramas. 
GALDINO, C. Programa de Gestão do Patrimônio Arqueológico do município de São Sebastiāo. Revista do Museu de Arqueolo. gia e Enologia, São Paulo, Suplemento 11: 183-188, 2011.

No tocante às ações de disponibilização do patrimônio arqueológico, utilizaremos como referência os preceitos fornecidos por Rossano Lopes Bastos, ao afirmar "sobre maneiras como os sítios arqueológicos podem ser estudados e sobre os benefícios derivados para o público no estudo e conservação de recursos arqueológicos. Aqui, o objetivo é fazer Arqueologia tanto pública como publicamente relevante" (2006: 157). Os trabalhos serão realizados segundo os preceitos da Arqueologia Pública, definida como a ramificação "voltada ao relacionamento entre a pesquisa e o manejo de bens culturais com os grupos sociais interessados, de forma a promover a participação da sociedade na gestão de seu patrimônio arqueológico histórico" (RobrahnGonzáles2006: 64).

Pedro Paulo Funari e Erika RobrahnGonzález afirmam que o "aspecto público da Arqueologia refere-se à atuação com as pessoas", onde destaca a participação de comunidades diretamente envolvidas e o público estudantil (2006: 3). Assim, levamos adiante procedimentos que prezam pela participação da comunidade $\mathrm{e}$ a utilização do patrimônio arqueológico como subsídio às atividades educativas e econômicas, consoante com as palavras de Matilde González Méndez (2000: 20):

"Por su parte, el fenómeno de patrimonialización de los elementos arqueológicos, en su forma más estricta, se genera igualmente a partir del pasado siglo cuando, entre otras circustancias, se comienza a tomar conciencia del interes que para el conocimiento del pasado possen los restos (independientemente de su magnificencia o belleza que ya se consideraban antes), de su utilidad para legitimar la particularización de un territorio, de su vulnerabilidad a los procesos de urbanización y ahora, de la capacidad de transformarse en recurso para el deleite social o la actividad economica"

Diante do exposto, realizamos algumas atividades, em conjunto com a prefeitura, no âmbito municipal, referentes ao estímulo à apropriação do patrimônio arqueológico pela comunidade sebastianense. Dentre as atividades realizadas, destacamos o Curso de Formação de Monitores Ecológico-Culturais (Fig. 2). Tal

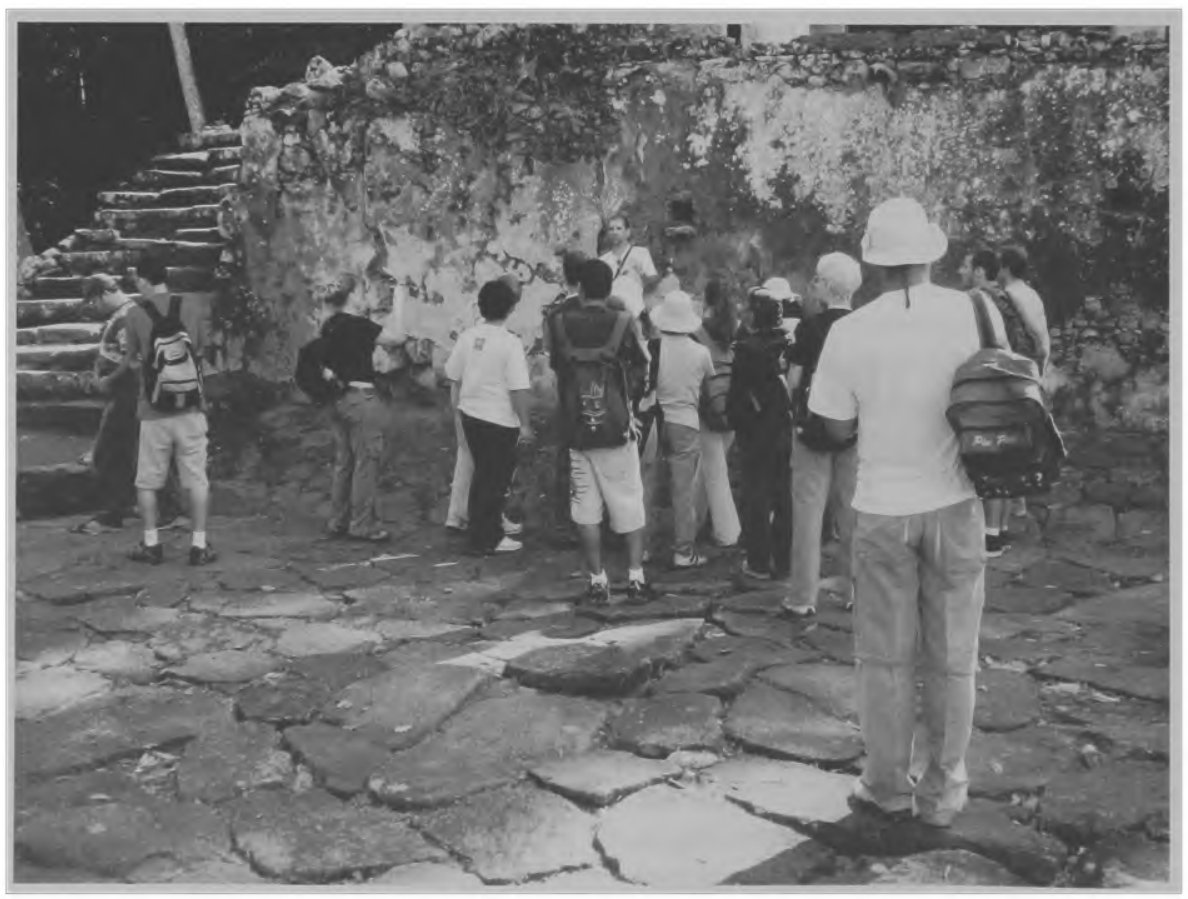

Fig. 2. Curso de Formação de Monitores Ecológico-Culturais. Fonte: acervo do autor. 


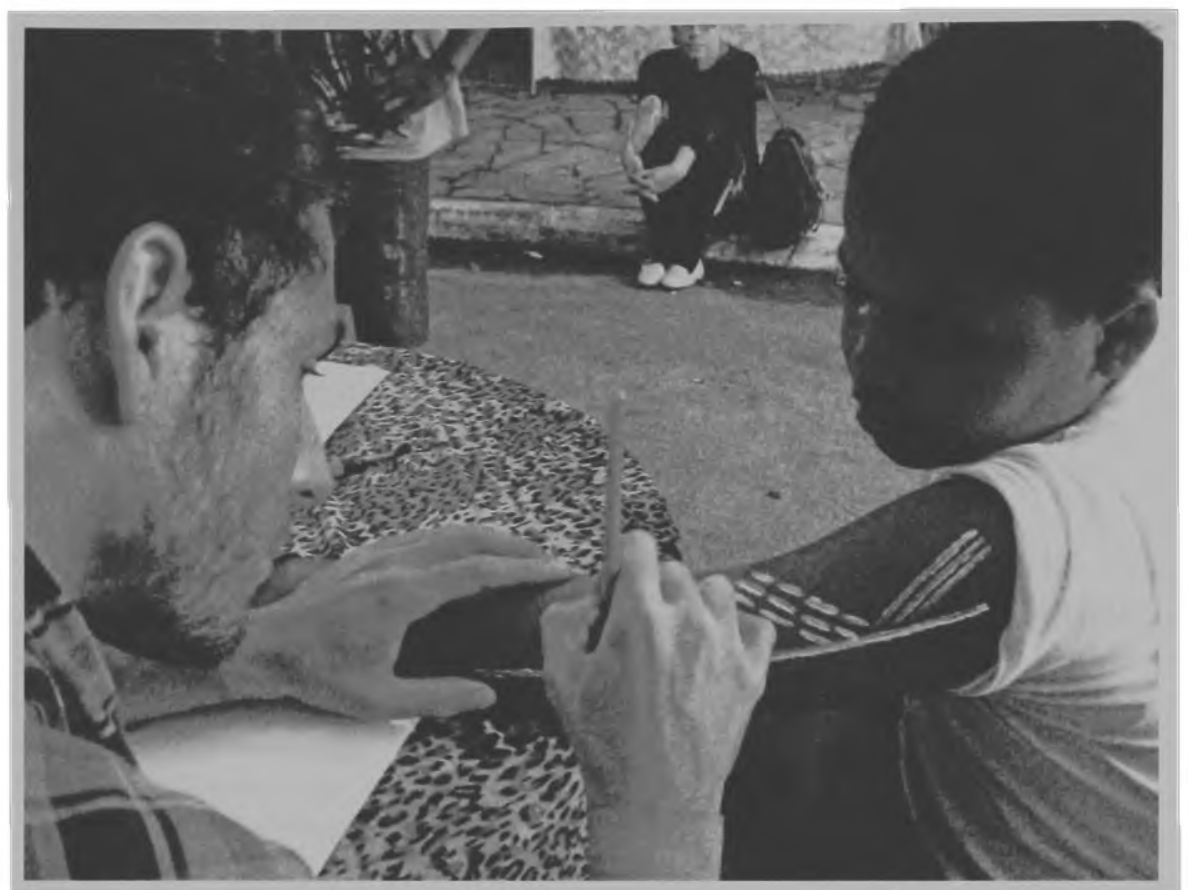

Fig. 3. Pintura corporal étnica realizada na 1 a Semana do Congadeiro, com motivos encontrados nos fragmentos arqueológicos. Fonte: acervo do autor.

iniciativa referiu-se à formação de corpo de monitores especializados no contexto caiçara e africano presente no Sítio Arqueológico São Francisco.

Outra atividade, realizada em parceria com ONGs da região e com o Projeto Arqueológico São Francisco, foi a celebração da Congada de São Sebastião, durante a $1^{\text {a }}$ Semana do Congadeiro do Bairro de São Francisco da Praia. Nesse evento, foram oferecidas à comunidade diversas atraçōes, sob o enfoque do patrimônio imaterial e arqueológico (Fig. 3).

Finalizando, citaremos o projeto "A terapêutica da natureza através do barro". Realizado desde 2008, essa iniciativa foi submetida à seleção pública intitulada Petrobras Comunidades, na qual foi contemplada. O projeto teve como objetivo ministrar aulas de artesanato em barro a 130 alunos da APAE - Associação de Pais e Amigos do Excepcional, de São Sebastião, de segunda a sexta-feira, com duração de quatro horas diárias. As atividades tinham como referência os vestígios cerâmicos encontrados no Sítio Sāo Francisco - fragmentos de panelas, cabos, cachimbos, iconografia incisa - embora o objetivo maior fosse apenas o caráter terapêutico fornecido pelo manusear do barro.

\section{Considerações finais}

O presente trabalho procurou demonstrar, de forma sintética, o estado atual de nossa pesquisa, bem como os resultados parciais obtidos. Dessa forma, pretendemos explanar sobre as potencialidades da Arqueologia como vetor de desenvolvimento social. Embora esta ciência esteja imbuída de especialização e complexidade, faz-se necessário incrementar a percepção de sua utilidade cotidiana pela sociedade em geral.

Acreditamos que o patrimônio arqueológico pode e deve ser utilizado como plataforma em projetos educacionais e sociais, em especial como suporte a atividades pedagógicas e no fomento à economia criativa. Para esse objetivo, obtivemos o apoio e a participação de diferentes segmentos da sociedade de São Sebastião. Desta forma, o patrimônio arqueológico presente atua como importante contribuinte para o fortalecimento da identidade local. 
GALDINO, C. Program for Archaeological Heritage Management in São Sebastião. Revista do Museu de Arqueologia e Etnologia, São Paulo, Suplemento 11: 183-188, 2011.

Abstract: Under the supervision of Professor Maria Cristina M. Scatamacchia, this paper aims to provide bases for the consolidation of public politics for archaeological heritage in São Sebastião, SP. To this end, it recommends action recognitions and management, application and proposal of legislation, the curator of the collection and co-management of the archaeological community. This initiative has already obtained partial results that delineate their ultimate objectives.

Keywords: Management of archaeological heritage - Public Archeology Information systems.

\section{Referências bibliográficas}

BASTOS, R.L.

2006 A Arqueologia Pública no Brasil: novos tempos. In: Mori, V.H. et al (Orgs.) Patrimônio: atualizando o debate. São Paulo, $9^{a}$ SR/IPHAN: 155-169.

BORNAL, W.G.; GALDINO, C.

2009 Programa de Gestão do Patrimônio Cultural de São Sebastião. São Sebastião: Fundação Cultural de São Sebastião.

CHAGAS, J.L.

2010a SIGWeb para o patrimônio cultural (software). São Sebastião: Fundação Cultural São Sebastião.

2010b Inventário Digital do Patrimônio Cultural (software). São Sebastião: Fundação Cultural São Sebastião.

FUNARI, P.P.A.; ROBRAHN-GONZÁLES, E.M.

2006 Revista Arqueologia Pública, 1. Campinas: Unicamp.

ROBRAHN-GONZÁLES, E.M.

2006 Arqueologia e sociedade no município de Ribeirão Grande, Sul de São Paulo: açōes em Arqueologia Pública ligadas ao Projeto de Ampliação da Mina Calcária Limeira. Revista Arqueologia Pública, 1. Campinas: Unicamp: 63-123.

\section{MÉNDEZ GONZÁLEZ M.}

2000 Sistemas de evaluación del interes patrimonial de los yacimientos arqueológicos. In: López, M.M.B. (Org.) Gestión patrimonial y desarrollo social. CAPA 12. Santiago de Compostela, Laboratório de Arqueoloxía e Formas Culturales: 19-35.

MORAIS, J.L.

1992 Plano cartográfico do Projeto Paranapanema. Revista do Museu de Arqueologia e Etnologia, São Paulo, 2: 155-157.

1999 A Arqueologia e o fator geo. Revista do Museu de Arqueologia e Etnologia, São Paulo, 9: 3-22.

SCATAMACCHIA, M.C.M.

2008 Projeto Arqueológico Baixo Vale do Ribeira, São Paulo. São Paulo: MAE-USP.

SOARES, M.V.P.

2007 Proteção jurídica do patrimônio arqueológico. Fundamentos para efetividade da tutela em face de obras e atividades impactantes. Erechim: Hábilis.

ZANETTINI, P.E.

2003 Programa de diagnóstico histórico, cultural e arqueológico: Programa de Transporte Urbano de São Bernardo do Campo. São Paulo: Zanettini Arqueologia. 